treatment by general practitioners. The main finding was that treatment by specialist mental health professionals was about $10 \%$ more successful than that usually given by general practitioners. Counselling (including social work), behaviour therapy, and general psychiatry proved to be similar in their overall effect. The influence of counselling seemed to be greatest on social functioning, whereas behaviour therapy seemed mainly to reduce contacts with the extramural psychiatric services.

General practitioners are currently collaborating with paramedical workers and statutory and voluntary agencies to provide the overwhelming bulk of psychiatric care in Britain. At the same time general practitioners in many parts of Britain have no.alternative to referring patients to a psychiatrist. The evidence supports the effectiveness of the different therapeutic approaches, though none of the studies is entirely satisfactory. Moreover, most of the advantages of intervention by a non-psychiatrist have been shown in patients with nonpsychotic disorders. The role and skills of psychiatrists in reinforcing the effectiveness of the general practitioner and the primary care team remains an unresolved issue.

GREG WILKINSON

Senior Lecturer,

General Practice Research Unit,

Institute of Psychiatry,

London SE5 8AF

1 Kessel N. Who ought to see a psychiatrist? Lancet 1963;i:1092-4.

2 Shepherd M, Cooper B, Brown AC, Kalton G. Psychiatric illness in general practice. Oxford: Oxford University Press, 1966.

3 Brooker CGD, Simmons SM. A study to compare two models of community psychiatric nursing care delivery. $\mathcal{F}$ Adv Nurs 1985;10:217-23.

4 Robertson $\mathrm{H}$, Scott DJ. Community psychiatric nursing: a survey of patients and problems. $\mathcal{F} R$ Coll Gen Pract 1985;35:130-2.
5 Paykel ES, Mangen SP, Griffith JH, Burns TP. Community psychiatric nursing for neurotic patients: a controlled study. Br f Psychiatry 1982;140:573-81.

6 Mangen SP, Paykel ES, Griffith JH, Burchell A, Mancini P. Cost-effectiveness of community psychiatric nurse or outpatient psychiatrist care of neurotic patients. Psychol Med 1983;13: 407-16.

7 Marks IM. Psychiatric nurse therapists in primary care. The expansion of advanced clinical roles in nursing. London: Royal College of Nursing of the United Kingdom, 1985.

8 Marks I. Controlled trial of psychiatric nurse therapists in primary care. Br Med f 1985;290:1181-4.

Brisco M. Identification of emotional problems in postpartum women by health visiors. Br Medf 1986;292:1245-7.

$1986 ; 292: 1245-7$.
0 Corney RH. Social work effectiveness in the management of depressed women: a clinical trial. Psychol Med 1981;11:417-23.

11 Corney RH. The effectiveness of attached social workers in the management of depressed female patients in general practice. Psychol Med 1984;14(monograph suppl 6):47.

12 Ross $M$, Scott $M$. An evaluation of the effectiveness of individual and group cognitive therapy in the treatment of depressed patients in an inner city health centre. $f$ R Coll Gen Pract 1985;35:239-42. 3 Earll L, Kincey J. Clinical psychology in general practice. $\mathcal{F} R$ Coll Gen Pract 1982;32:32-7.

14 Ives G. Psychological treatment in general practice. $\mathcal{F} R$ Coll Gen Pract 1979;29:343-51.

$15 \mathrm{Koch} \mathrm{HCH}$. Evaluation of behaviour therapy intervention in general practice. $\mathcal{F} R$ Coll Gen Pract 1979;29:337-40

6 Robson $\mathrm{MH}$, France R, Bland $M$. Clinical psychologist in primary care: controlled clinical and economic evaluation. Br Med f 1984;288: 1805-8.

7 Blakey R. Psychological treatment in general practice: its effect on patients and their families. $\mathcal{f} R$ Coll Gen Pract 1986;36:209-11.

18 Blackburn IM, Bishop S, Glen AIM, Whalley LJ, Christie JE. The efficacy of cognitive therapy in depression: a treatment trial using cognitive therapy and pharmacotherapy, each alone and in depression: a treatment trial using cognitive
combination. Br $f$ Psychiatry 1981;139:181-9.

19 Teasdale JD, Fennell MJV Hibbert GA Amies PL. Cognitive therapy for major depressive disorder in primary care. Br $\mathcal{A}$ Psychiatry 1984;144:400-6.

20 Trepka C, Laing I, Smith S. Group treatment of general practice anxiety problems. $f R$ Coll Gen Pract 1986;36:114-7.

21 Anderson S, Hasler JC. Counselling in general practice. $\mathcal{F} R$ Coll Gen Pract 1979;29:352-6.

22 Martin E, Mitchell H. A counsellor in general practice: a one-year survey. $\mathcal{F} R$ Coll Gen Pract 1983;33:366-7

23 Ashurst PM, Ward DF. An evaluation of counselling in general practice. London: Mental Health Foundation, 1983. (Final report of the Leverhulme Counselling Project.)

24 Martin E, Martin PML. Changes in psychological diagnosis and prescription in a practice employing a counsellor. Fam Pract 1985;2:241-3.

25 Corney RH. Marriage guidance counselling in general practice in London. British fournal of Guidance and Counselling 1987;15:50-8.

26 Balestrieri $M$, Williams $P$, Wilkinson G. Specialist mental health treatment in general practice: a meta-analysis. Psychol Med 1988:18:711-7.

27 McKechnie AA, Philip AE, Ramage JG. Psychiatric services in primary care: specialised or not? JR Coll Gen Pract 1981;31:611-4.

28 Tyrer P, Seivewright N, Wollerton S. General practice psychiatric clinics: impact on psychiatric services. Br f Psychiatry 1984;145:15-9.

29 Cooper B. Harwin BJ, Depla C, Shepherd M. Mental health care in the community: an evaluative study. Psychol Med 1975;5:372-80.

30 Shepherd M, Harwin BG, Depla C, Cairns V. Social work and the primary care of mental disorder. Psychol Med 1979;9:661-9.

\title{
Orthotic services: a need for change
}

\section{Separate the fees for fitting and manufacturing}

The service to provide external splints and appliances-now called orthoses-has been virtually privatised since the beginning of the NHS. It costs about $£ 38 \mathrm{~m}$ yearly. About 130 different firms tender prices for a year at a time for supplying some 1400 different standard orthoses. The firm chosen to supply a hospital will send their fitter (or orthotist) to attend clinics. The patient is measured or a cast made, and the appliance is eventually fitted. The contract states that this must be done within six weeks.

There have been complaints about the orthotic (and prosthetic) service for years, and several reports have made essentially similar recommendations. ${ }^{1-4}$ The consensus is that patients are not getting the service or the technology that is available. The reports have recommended that orthotic and prosthetic services should be less separated, that the NHS hospital workshops (currently constituting less than $3 \%$ of the service) should be fostered, and that the contracting system should be changed.

One problem is the way that orthotists' services are organised. Several district health authorities have examined their orthotic services, and Southampton Health Authority has, for example, concluded that it could save up to $£ 68000$ a year by employing its own orthotist manager. ${ }^{5}$ Bristol and Weston Health Authority has been doing this for years, and Bloomsbury Health Authority would if it could recruit orthotists. The Whitley scales of pay for NHS orthotists (on the rates of medical physics technicians) are, however, some $£ 2000-4000$ a year less than the salaries available in the private sector-not counting the car and other perks commonly available. They are thus insufficient to attract (or retain) orthotists. Health authorities seeking to employ their own orthotists have to resort to devious arrangements to find salaries approaching those in the commercial sector.

The contract price, which is now agreed by district health authorities, is for both fitting and supplying orthoses. The price is the same, for example, for a calliper for an easily fitted, normally shaped leg as for a calliper for a difficult leg requiring multiple fittings and much skill and attention from the orthotist. Under the present system these cases present a difficulty for commercial orthotists, who have a professional duty to the patient and a commercial responsibility to their employer. Too often the patient is left with an ill fitting, ugly, and non-effective appliance.

If the charges for the two distinct parts of the service-that is, fitting (including casting, measuring, and so on) and manufacturing - were to be separated orthotists could be paid directly for their principal duties: fitting patients. If their employment was unconnected with the commercial aspects of manufacture they would be better able to select impartially the best buy for the patient (and the economy). Hospital 
managements buying orthotists' services directly would be more likely to ensure better use of their time, and patients would be better served.

A mechanism to provide a contract for orthotists' services is urgently needed. Whitley scales will always lag behind the commercial sector, and the present government is unlikely to nationalise orthotists. As suggested by McColl for prosthetists, ${ }^{6}$ orthotists might be persuaded to become independent and self employed or even to get together and form a contracting service independent of manufacturers.

With the prosthetic and wheelchair services coming into the NHS on a regional basis by 1991 we have an opportunity to integrate prosthetic and orthotic services and rehabilitation engineering into centres of excellence. Each centre should be associated with a university to attract research and innovation, help lift the service out of the doldrums, and provide those who are chronically disabled with the best technology.

Senior Lecturer and Honorary Consultant,

R G S PLATTS

Institute of Orthopaedics,

Stanmore,

Middlesex HA7 4LP

1 British Medical Association. Aids for the disabled. Planning Unit report No 2. 2nd ed. London: BMA, 1969. (Guthrie report.)

2 Department of Health and Social Security. Rehabilitation. Report of a subcommittee of the Standing Medical Advisory Committee. London: HMSO, 1972. (Tunbridge report.)

3 British Orthopaedic Association. Report of committee on prosthetic and orthotic services in England, Wales and Northern Ireland. London: Royal College of Surgeons, 1973.

4 Royal Association for Disability and Rehabilitation. A future for the orthotic service. A report by a working party on the availability and supply of orthotic appliances. London: RADAR 1982.

Southampton Health Authority. Review of orthoses and special footwear services. Southampton: SHA, 1986.

$6 \mathrm{McColl}$ I. Review of artificial limb and appliance centre services. London: HMSO, 1986.

\section{Genital herpes during pregnancy}

\section{Routine virological screening is futile}

Neonatal herpes infection occurs in about one in 500 pregnancies in parts of the United States ${ }^{1}$ but is rare in Britain. Between 1976 and 1985 there were over six million births in England and Wales but only 18 neonatal deaths from herpes and 111 laboratory identifications of the virus in neonates (not all of which were necessarily associated with illness) (N S Galbraith, personal communication). Herpes infection of the new born is thus much less common than infection with genital herpes simplex virus in women of reproductive age. The transmission of herpes infection from mother to the fetus or baby is high (40\%) in primary maternal infection but low $(3 \%)$ in recurrent maternal infection.

At the Birmingham Maternity Hospital, where 5000 babies a year are delivered, there have been two neonatal deaths from disseminated herpes infections over the past 10 years. Both mothers were without symptoms and gave no history of infection. The first baby, delivered at term by forceps because of delay in the second stage of labour, was well for the first two days and died on the seventh day; maternal swabs taken on the eighth day showed herpes. The second baby was born at 33 weeks' gestation by caesarean section because of a compound presentation in early labour and a suspicion of malignancy of the cervix. This baby died on the 12th day; virological investigations were not performed at the time, and later viral investigations gave negative results. The woman had a normal delivery of a healthy infant 13 months later. The delivery of the baby who died occurred at a time when we were screening all mothers with a history of genital herpes, and the prevalence at that time in our hospital was $0 \cdot 6 \% .^{2}$ No swab gave positive results for herpes infection in the mother of the baby who died.

Screening has been advocated by some ${ }^{3}$ and questioned by others. ${ }^{+}$Large studies have shown, however, that maternal cultures taken before birth do not predict which infants are at risk of exposure to herpes simplex virus at delivery. ${ }^{5}$ In one study herpes simplex virus was shed during labour in 14 out of $6904(0 \cdot 2 \%)$ consecutive patients. ${ }^{6}$ Only one of the 14 women had a history of genital herpes whereas 12 had serological evidence of a previous infection. The laboratory takes three to four days to recognise the patients who are without symptoms but are shedding the virus: the information is thus of no value in labour but may be useful to the paediatrician. Asymptomatic shedding of the virus is, however, brief - probably less than three days. Brown, in a large study lasting over eight years, recalled immediately every patient who had positive results on culture during pregnancy and yet did not have positive results when the culture was repeated.?

The huge increase in caesarean sections, particularly in the United States, because of possible herpes infection in the mother has been questioned ${ }^{8}$ because of increased maternal and neonatal mortality and morbidity. It has generally been assumed that if caesarean section is done before the membranes rupture the baby is safe, but at least 19 cases of neonatal herpes have occurred when the caesarean section was performed before the membranes ruptured. ${ }^{9}$ Intrauterine infection is probably not as rare as has been thought.

What this means for the practising obstetrician and neonatal paediatrician is that it is futile to do routine cultures on women entering pregnancy with a history of genital herpes. Instead, all women entering labour should have a careful history taken about any recent herpes infection in themselves or their partner. Patients giving a history of recent infection should have an examination of the vagina and the cervix with a speculum and a tactile examination of the external genitalia.

If there is any suggestion of a lesion on digital examination the patient should be examined with a speculum. All women with premature rupture of the membranes have such an examination, and any suspicious lesions should be noted and virological studies performed if necessary.

If a lesion suspicious of herpes is seen swabs should be taken for culture and the women considered for delivery by caesarean section if labour is in the early stages. If there is no obvious lesion in the genital tract vaginal delivery should be allowed. If labour is progressing rapidly the baby is probably already infected and should be managed accordingly.

The evidence suggests that routine use of oral acyclovir in pregnancy in women in whom herpes infection is reported should be discouraged, but acyclovir may be useful for the patient with a herpes lesion on the cervix at around 32 weeks' gestation. Brown gave a 14 day course of acyclovir to such a patient, who subsequently delivered normally a healthy infant (Z A Brown, personal communication).

Infants exposed to asymptomatic viral shedding during labour should have specimens for virological investigations taken from the eyes, nasopharynx, umbilicus, and any abrasions caused by forceps or puncture sites from scalp electrodes. Maternal serum samples should be examined to see whether the infection is primary or recurrent. Acyclovir 